\title{
Influence of class size on physical activity behavior changes in a 15-week health-related fitness course
}

\author{
Mitchell A. Collins ${ }^{1}$ \\ Mauro V.G. Barros ${ }^{2}$ \\ Markus V. Nahas ${ }^{3}$ \\ Bernie Goldfine ${ }^{1}$ \\ Angela B. Lanier ${ }^{1}$ \\ Jennifer Beck ${ }^{1}$
}

\author{
${ }^{1}$ Department of Health, \\ Physical Education and Sport Science \\ Kennesaw State University, Kennesaw, GA, USA \\ ${ }^{2}$ Universidade de Pernambuco, Recife, PE, Brasil \\ ${ }^{3}$ Centro de Desportos, Universidade Federal de Santa \\ Catarina, Florianópolis, SC, Brasil
}

\begin{abstract}
Objective - The purpose of this study was to determine if class size in a health-related fitness course affects physical activity behaviors of urban, commuter university students.

Methods - Survey questions related to physical activity behaviors were administered to 653 students enrolled in small $(\sim 40$ students) or large ( $\sim 100$ students) health-related fitness courses (small experimental, SE or large experimental, LE) designed to promote positive physical activity patterns or a control group (C). The data were analyzed using ANOVA and Chi-Square tests.

Results - Following the 15-week intervention, patterns emerged suggesting that the SE was more effective than the LE in eliciting increases in the quantity and quality of physical activity. When the data were dichotomized to reflect compliance with minimal standards, the SE group had a significantly $(\mathrm{p}<.05)$ greater proportion of subjects compared to the LE group who reported exercising $150^{+}$minutes/week (14.6\% vs $5.3 \%$, respectively) and who achieved $450^{+}$MET minutes/week of physical activity ( $17.3 \%$ vs $4.6 \%$, respectively). For the subjects classified in the active stages of change (action and maintenance), only the LE group ( $7.4 \%$ change) reported a significant increase $(\mathrm{p}<.05)$ in the proportion who were active, though a trend for the SE group (9.6\% change) to increase $(p=.066)$ was observed. Regarding physical activity enjoyment, there were no differences found among groups. Conclusion Based on the findings from the present study, class size in a 15 -week health-related fitness course appears to affect changes in physical activity behaviors. Therefore, if a primary goal of health-related fitness courses is to increase participation in physical activity, it would be a prudent policy to limit enrollment in such courses.
\end{abstract}

Key Words: Intervention studies, health behavior, exercise, physical activity.

\section{RESUMO}

Influência do tamanho da turma nas mudanças da atividade física numa disciplina de atividade física e saúde

Objetivo - O objetivo deste estudo foi determinar se o tamanho da turma numa disciplina sobre atividade física e saúde influencia a mudança nos níveis de atividade física habitual de universitários da Kennesaw State University, na Geórgia, EUA. Métodos - Um questionário foi aplicado a 653 estudantes matriculados em turmas pequenas ( $\sim 40$ alunos) ou grandes ( $\sim 100$ alunos) de uma disciplina de formação geral sobre atividade física e saúde (experimental pequena, EP, ou experimental grande, EG). Um grupo controle foi formado por alunos que não freqüentavam tal disciplina. Os dados foram analisados utilizando ANOVA e teste do Qui-quadrado. Resultados - Depois de 15 semanas de aulas (um semestre letivo), observou-se que as turmas com menos alunos promoveram mudanças de comportamento (atividade fisica) mais efetivas. Quando os dados foram agrupados, refletindo o atendimento ou não aos critérios mínimos de referência de atividades físicas, as turmas pequenas (EP) tinham uma proporção significativamente maior de sujeitos que atendiam a esses critérios $(p<0,5): 150^{+}$ minutos/semana ( $E P=14,6 \% ; E G=5,3 \%) ; 450^{+}$MET.minutos $/$semana de atividade física $(E P=17,3 \% ; E G=4,6 \%)$. Para os sujeitos classificados nos estágios de mudança de comportamento considerados ativos (ação e manutenção), somente o EG teve mudança significativa após o semestre $(+7,4 \%$; $p<0,05)$. Para o grupo EP, a variação observada foi de $+9,6 \%(p<0,66)$. Quanto ao nível de satisfação com as atividades físicas, não se observou diferença entre os grupos. Conclusões - Os resultados deste estudo permitem concluir que o tamanho da turma, numa disciplina geral sobre atividade fisica e saúde, ministrada durante um semestre letivo (15 semanas) parece influenciar as mudanças nos níveis de atividade fisica. Assim, se um dos objetivos principais de disciplinas como esta for aumentar a participação dos universitários em atividades físicas, seria adequado limitar o número de alunos por turma.

Palavras-chave: estudos de intervenção, mudança de comportamento, exercício, atividade física. 


\section{INTRODUCTION}

Physical inactivity is associated with an increased risk of chronic disease including cardiovascular disease, cancer, and diabetes $(14,16)$. In the 1996 U.S. Surgeon General's report, it was concluded that moderate amounts of physical activity performed on most days of the week can substantially improve one's health and quality of life (15). Despite the documented benefits of physical activity, most industrialized countries continue to have a high prevalence of their population with sedentary behavior (15).

To address the public health concern of physical inactivity, universities began the incorporation of multidimensional, health-related concepts courses into their basic instructional programs in the 1980s. These courses were designed to facilitate lifelong participation in physical activity, improve fitness, and to help students understand the importance of physical activity in their lives. Although about 52\% of the universities in the U.S. offer a health-related fitness course (5), there is limited research on the impact of such courses on lifelong physical activity behavior $(1,13)$. It was concluded in a recent report that there are insufficient data to determine if current educational programs in universities are effective at increasing physical activity behaviors and fitness levels of students (2).

With changing economic times in the late 1990s, universities were forced to either eliminate basic instructional programs or to find ways to deliver academic programs in a more cost effective manner. One strategy often employed by university administrators is to increase class size. Though this may be a cost effective and simple solution for the delivery of programs, it is imperative to examine the impact of such actions on student learning outcomes.

However, no studies were found specifically addressing the effect of increased class sizes in university settings on exercise behaviors. If learning outcomes are impaired by increases in class size that are too large, it would be prudent for university administrators to determine the threshold class size necessary to meet course objectives. Therefore, the purpose of this study was to determine if class size in a healthrelated fitness course affects physical activity behaviors of urban, commuter university students.

\section{METHODS}

\section{Research Design}

This 15-week epidemiological intervention study was designed to determine the influence of class size on the effectiveness of a health-related fitness course to alter the mediators and level of physical activity. Pre test and post test measures were made during week 1 and week 15 of the study. The theoretical background supporting the methodological basis for this research was recently published (12).

\section{Subjects}

Subjects for the study were selected based on meeting specific criteria for eligibility in either the control or experimental groups. The control subjects were identified via a computerized evaluation of freshman-level general education classes that had the highest proportion of students who had never enrolled in the university-wide health-related fitness course. Fourteen classes with enrollments of approximately 25 students each were selected to participate in the survey. Only students from these classes who had never enrolled in the health-related fitness course were surveyed. Sixteen of 41 classes of the health-related fitness course were selected to participate in the study. The criteria for class selection were based on the teaching experience of the instructor, knowledge of behavioral intervention strategies, and a record of quality instruction. Based on the above criteria, a total of 1136 subjects were eligible to participate in the study; however, only 653 (54\%) completed the entire project.

To determine the effect of class size, the subjects were partitioned into three groups: small experimental, SE ( $n=144 ; \sim 40$ students per health-related fitness course); large experimental, LE $(n=424 ; \sim 100$ students per health-related fitness course); or control, $C$ ( $n=85$; general education courses). There were no differences ( $p>.05)$ among the SE, LE, and $\mathrm{C}$ groups with regard to age, gender, marital status, or race (Table 1). This study was reviewed and approved by the Institutional Review Board for use of human subjects at Kennesaw State University. All subjects provided a written informed consent prior to participation in the study. 
Table 1. Demographics of subjects.

\begin{tabular}{|c|c|c|c|}
\hline Variable & $\begin{array}{l}\text { Small Experimental Group } \\
\qquad(n=144)\end{array}$ & $\begin{array}{l}\text { Large Experimental Group } \\
\qquad[\mathrm{n}=424]\end{array}$ & $\begin{array}{l}\text { Control Group } \\
\qquad(n=85]\end{array}$ \\
\hline \multicolumn{4}{|l|}{ Age, years } \\
\hline $17-25$ & $119(82.6 \%)$ & 347 (81.8\%) & $62(72.9 \%)$ \\
\hline $26-35$ & $16(11.2 \%)$ & $50(11.8 \%)$ & $14(16.5 \%)$ \\
\hline$>35$ & $9(6.3 \%)$ & $27(6.4 \%)$ & $9(10.6 \%)$ \\
\hline \multicolumn{4}{|l|}{ Gender } \\
\hline Males & $53(36.8 \%)$ & $150(35.4 \%)$ & $20(23.5 \%)$ \\
\hline Females & 91 (63.2\%) & 274 (64.6\%) & 65 (76.5\%) \\
\hline \multicolumn{4}{|c|}{ Marital Status } \\
\hline Single & 112 (77.8\%) & 329 (77.8\%) & $62(72.9 \%)$ \\
\hline Married & $20(13.9 \%)$ & $60(14.2 \%)$ & $16(18.8 \%)$ \\
\hline Divorced & $4(2.8 \%)$ & 8 [1.9\%) & $2(2.4 \%)$ \\
\hline Other & $8(5.6 \%)$ & $26(6.1 \%)$ & $5(5.9 \%)$ \\
\hline \multicolumn{4}{|l|}{ Race } \\
\hline White & 124 (86.1\%) & $358(84.6 \%)$ & 75 (88.2\%) \\
\hline Black & $7(4.9 \%)$ & 34 (8.0\%) & 6 (7.1\%) \\
\hline Hispanic & $1(0.7 \%)$ & $15(3.5 \%)$ & $2(2.4 \%)$ \\
\hline Other & $12(8.4 \%)$ & $16(3.8 \%)$ & $2(2.4 \%)$ \\
\hline
\end{tabular}

\section{Instrument}

The survey consisted of previously validated questions related to physical activity behaviors (IPAQ 6.0; current version of the IPAQ can be found at $h t t p: / / w w w . i p a q . k i . s e)$, physical activity enjoyment (6), and the stages of change (10). An independent test-retest reliability $(n=30)$ for the survey instrument questions was performed prior to the study, and yielded reliability coefficients ranging from .58 .95. To ensure consistency, members of the research team utilizing standardized instructions administered all surveys.

\section{Intervention}

The 15-week health-related fitness course entailed a lecture component where fitness and health concepts were presented. In addition, there was a laboratory component where basic assessments of cardiovascular endurance, muscular fitness, body composition, and flexibility were performed. Though there was not a structured physical activity component in the course, several classes during the semes- ter were used to expose students to various types of activity from aerobic type activities (e.g., step aerobics) to more game-type activities (e.g., ultimate frisbee). In the health-related fitness course, a major goal was to promote positive physical activity patterns using behavioral change strategies such as goal setting and assessment, peer group strategy and reenforcement, and the development of personalized exercise prescriptions. To ensure consistency of content delivery for the SE and LE groups, the same instructors taught both the small and large sections of the course. Subjects in the $\mathrm{C}$ group were not enrolled in the health-related fitness nor had they previously taken a similar college course.

\section{Variables}

Physical activity levels were determined from questions related to the frequency and duration of vigorous (causes hard breathing and rapid heart rate), moderate (moderately increases breathing and heart rate, but excludes walking), and walking exercise. These questions were adapted from the International 
Physical Activity Questionnaire (IPAQ). A measure of time engaged in each activity was used to estimate the total minutes of physical activity per week. MET minutes/ week of physical activity was estimated using a MET value of 3 for moderate/ walking activity and 7 for vigorous activity. One MET is an equivalent of a person's resting metabolic rate, or $3.5 \mathrm{ml} / \mathrm{kg} / \mathrm{min}$ of oxygen consumption. It is assumed that any errors in the estimated MET minutes/week values will be systematic across groups. Subjects were dichotomized into categories based on compliance with accumulating a threshold of $150^{+}$ minutes/week of activity and for meeting the $450^{+}$ MET minutes/week level.

Stage of change was determined for each subject based on responses to five questions. Each subject was classified into one of five stages: precontemplation, contemplation, preparation, action, and maintenance. A more detailed description is found elsewhere (10). In addition, subjects were dichotomized into categories based on perceiving themselves as being inactive (precontemplation, contemplation or preparation) or active (action or maintenance). Physical activity enjoyment was determined from 18 seven-point semantic differential scale questions (6). Values were assigned to the scale from -3 (least enjoyment) to 3 (most enjoyment) based on a 0 neutral point (middle). A measure of overall physical activity enjoyment was estimated by summing the scores for all questions. In addition, subjects were dichotomized into categories based on having overall negative or positive feelings toward physical activity.

\section{Data Analysis}

All data analysis was performed using SPSS, version 10.0. The data were analyzed using ANOVA with Tukey post hoc test and a Chi-Square nonparametric analysis. To control for the potential effect of gender and age, the data were examined by using a stratified analysis. From the Chi Square analysis $2 \mathrm{X} 2$ tables, the Fisher's Exact Test was used to determine significance. In addition, simple descriptive statistics were computed. The alpha was set at the .05 level.

\section{RESULTS}

Pre test physical activity levels, stages of change, and physical activity enjoyment scores were not different ( $>$.05) among the groups. Figure 1 illustrates the percent change for vigorous, moderate, and walking physical activity levels among groups. Following the 15-week intervention, vigorous physical activity levels (MET minutes/week) tended to increase (about $6 \%)$ for the SE group while levels tended to decrease for the LE and C groups (about $-8 \%$ and $-20 \%$, respectively). For moderate physical activity levels (MET minutes/ week), the SE group increased approximately $22 \%$ while the LE group had a $10 \%$ increase and the $\mathrm{C}$ group decreased $-24 \%$. And for walking, all groups reported a small decrease in physical activity levels.

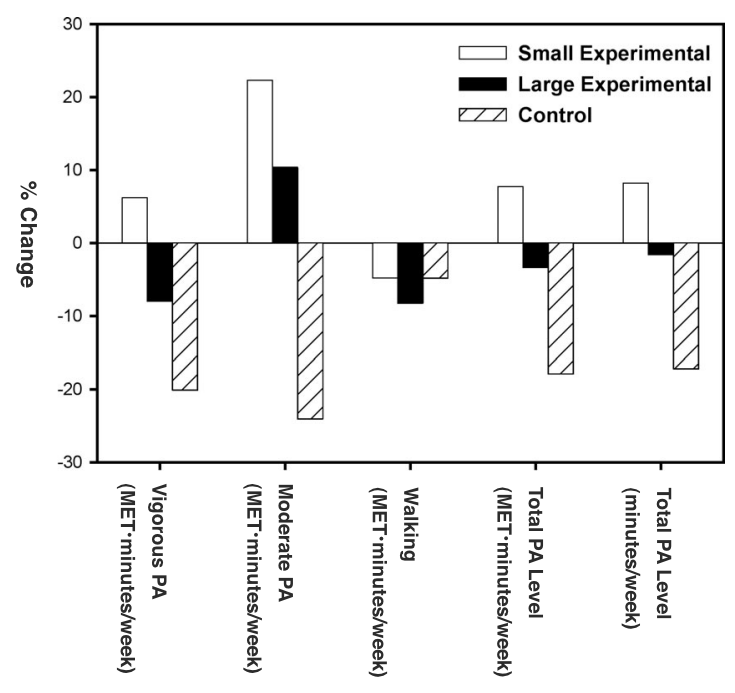

Figure 1. Change in physical activity behaviors.

When vigorous, moderate, and walking were combined to assess total physical activity level, similar patterns emerged (Figure 1). For total physical activity level (MET minutes/week), the SE group again tended to increase activity levels (about $8 \%$ ), while the $\mathrm{LE}$ and $\mathrm{C}$ groups reported decreases (about $-3 \%$ and $-18 \%$, respectively). For the quantity of total physical activity (minutes/week), the SE group tend- 
ed to increase (about $8 \%$ ), and the LE and C groups decreased (about $-2 \%$ and $-17 \%$, respectively). When the data were dichotomized to reflect compliance versus noncompliance (Table 2), significant differences $(p<.05)$ were observed among the groups. The SE group reported a significant increase $(\mathrm{p}<.05)$ in number of subjects $(14.6 \%)$ achieving $150^{+}$minutes/week of moderate/vigorous physical activity. There was no change for the LE or C groups. Similarly for achieving the $450^{+}$MET minutes/week physical activity level, the SE reported a $17.3 \%$ increase $(\mathrm{p}<.05)$, and the $\mathrm{C}$ group decreased $(-15.3 \% ; \mathrm{p}<.05)$ with no change for the LE group. When examining the stage of change for the subjects, the LE (7.4\%) and C $(-16.0 \%)$ both significantly changed $(\mathrm{p}<.05)$ the number of subjects in the active stages, and there was a non significant trend $(\mathrm{p}=.066)$ for the SE group to increase $(9.6 \%)$. With regard to physical activity enjoyment, none of the groups reported an increase in positive feelings toward physical activity.

Table 2. Changes in physical activity compliance, stages of change, and physical activity enjoyment.

\begin{tabular}{|c|c|c|c|}
\hline Variable & Pre Test & Post Test & $\Delta$ \\
\hline \multicolumn{4}{|l|}{$\begin{array}{l}150+\text { minutes/week of } \\
\text { moderate/vigorous physical } \\
\text { activity (\% compliance) }\end{array}$} \\
\hline Small Experimental Group & $60.4 \%$ & $75.0 \%$ & $14.6 \% *$ \\
\hline Large Experimental Group & $66.3 \%$ & $71.6 \%$ & $5.3 \%$ \\
\hline Control Group & $67.1 \%$ & $60.0 \%$ & $-7.1 \%$ \\
\hline \multicolumn{4}{|c|}{$\begin{array}{l}450+\text { MET.minutes/week of } \\
\text { moderate/ vigorous physical } \\
\text { activity (\% compliance) }\end{array}$} \\
\hline Small Experimental Group & $65.3 \%$ & $82.6 \%$ & $17.3 \% *$ \\
\hline Large Experimental Group & $75.1 \%$ & $79.7 \%$ & $4.6 \%$ \\
\hline Control Group & $78.8 \%$ & $63.5 \%$ & $-15.3 \% *$ \\
\hline \multicolumn{4}{|c|}{$\begin{array}{l}\text { Active (Action or Maintenance) } \\
\text { stages of change [\% of subjects] }\end{array}$} \\
\hline Small Experimental Group & $52.4 \%$ & $62.0 \%$ & $9.6 \%$ \\
\hline Large Experimental Group & $56.1 \%$ & $63.5 \%$ & $7.4 \% *$ \\
\hline Control Group & $56.5 \%$ & $40.5 \%$ & $-16.0 \% *$ \\
\hline \multicolumn{4}{|l|}{$\begin{array}{l}\text { Positive feelings regarding } \\
\text { physical activity enjoyment } \\
\text { (\% of subjects] }\end{array}$} \\
\hline Small Experimental Group & $79.6 \%$ & $86.6 \%$ & $7.0 \%$ \\
\hline Large Experimental Group & $85.3 \%$ & $89.0 \%$ & $3.7 \%$ \\
\hline Control Group & $78.0 \%$ & $86.9 \%$ & $8.9 \%$ \\
\hline
\end{tabular}

When a statistical analysis was performed using data stratification procedures based on gender (Table 3) and age (Table 4), the increase in the proportion of subjects achieving $150^{+}$minutes/week of moderate/vigorous activity was found only among females and subjects over 19 years of age within the SE group. Increases in the proportion of subjects in the SE group meeting the $450^{+}$MET minutes/week of moderate/vigorous physical activity were found to be among females and independent of age. For the active stages of change, the increase was found only among the females in the LE group. 
Table 3. Changes in physical activity compliance, stages of change, and physical activity enjoyment when stratified based on gender.

\begin{tabular}{|c|c|c|c|c|}
\hline \multirow[t]{2}{*}{ Variable } & \multicolumn{2}{|c|}{ Females $(n=430)$} & \multicolumn{2}{|c|}{ Males [ $n=223$ ] } \\
\hline & Pre Test & Post Test & Pre Test & Post Test \\
\hline \multicolumn{5}{|c|}{$\begin{array}{l}150+\text { minutes/week of moderate/ } \\
\text { vigorous physical activity (\% compliance) }\end{array}$} \\
\hline Small Experimental Group & $51.6 \%$ & $73.6 \% *$ & $75.5 \%$ & $77.4 \%$ \\
\hline Large Experimental Group & $62.1 \%$ & $69.0 \%$ & $74.0 \%$ & $76.5 \%$ \\
\hline Control Group & $61.5 \%$ & $56.9 \%$ & $85.0 \%$ & $70.0 \%$ \\
\hline \multicolumn{5}{|c|}{$\begin{array}{l}450+\text { MET.minutes/week of moderate/ } \\
\text { vigorous physical activity ( } \% \text { compliance) }\end{array}$} \\
\hline Small Experimental Group & $58.2 \%$ & $79.1 \% *$ & $77.4 \%$ & $88.7 \%$ \\
\hline Large Experimental Group & $71.0 \%$ & $76.6 \%$ & $82.9 \%$ & $85.2 \%$ \\
\hline Control Group & $73.8 \%$ & $58.5 \%$ & $95.0 \%$ & $80.0 \%$ \\
\hline \multicolumn{5}{|c|}{$\begin{array}{l}\text { Active [Action or Maintenance] } \\
\text { stages of change [ } \% \text { of subjects] }\end{array}$} \\
\hline Small Experimental Group & $50.5 \%$ & $59.6 \%$ & $55.8 \%$ & $66.0 \%$ \\
\hline Large Experimental Group & $48.7 \%$ & $58.6 \% *$ & $69.6 \%$ & $72.5 \%$ \\
\hline Control Group & $52.3 \%$ & $35.9 \%$ & $70.0 \%$ & $55.0 \%$ \\
\hline \multicolumn{5}{|c|}{$\begin{array}{l}\text { Positive feelings regarding physical } \\
\text { activity enjoyment [\% of subjects] }\end{array}$} \\
\hline Small Experimental Group & $74.4 \%$ & $82.2 \%$ & $88.5 \%$ & $94.2 \%$ \\
\hline Large Experimental Group & $85.6 \%$ & $87.5 \%$ & $84.7 \%$ & $91.9 \%$ \\
\hline Control Group & $79.0 \%$ & $86.2 \%$ & $75.0 \%$ & $89.5 \%$ \\
\hline
\end{tabular}

Table 4. Changes in physical activity compliance, stages of change, and physical activity enjoyment when stratified based on age.

\begin{tabular}{|c|c|c|c|c|}
\hline \multirow[t]{2}{*}{ Variable } & \multicolumn{2}{|c|}{$17-19$ years $(n=326)$} & \multicolumn{2}{|c|}{$20+$ years $(n=327)$} \\
\hline & Pre Test & Post Test & Pre Test & Post Test \\
\hline \multicolumn{5}{|c|}{$\begin{array}{l}150+\text { minutes/week of moderate/vigorous } \\
\text { physical activity [\% compliance) }\end{array}$} \\
\hline Small Experimental Group & $60.9 \%$ & $73.4 \%$ & $60.0 \%$ & $76.3 \% *$ \\
\hline Large Experimental Group & $64.3 \%$ & $67.2 \%$ & $68.3 \%$ & $75.4 \%$ \\
\hline Control Group & $60.0 \%$ & $57.1 \%$ & $75.0 \%$ & $62.8 \%$ \\
\hline \multicolumn{5}{|c|}{$\begin{array}{l}450+\text { MET.minutes/week of moderate/ } \\
\text { vigorous physical activity (\% compliance) }\end{array}$} \\
\hline Small Experimental Group & $62.3 \%$ & $79.7 \% *$ & $42.9 \%$ & $57.1 \% *$ \\
\hline Large Experimental Group & $73.3 \%$ & $75.9 \%$ & $45.8 \%$ & $54.2 \%$ \\
\hline Control Group & $77.8 \%$ & $59.5 \%$ & $52.5 \%$ & $47.5 \%$ \\
\hline \multicolumn{5}{|c|}{$\begin{array}{l}\text { Active [Action or Maintenance) } \\
\text { stages of change [\% of subjects] }\end{array}$} \\
\hline Small Experimental Group & $44.9 \%$ & $54.0 \%$ & $59.5 \%$ & $68.4 \%$ \\
\hline Large Experimental Group & $54.0 \%$ & $62.6 \%$ & $58.1 \%$ & $64.3 \%$ \\
\hline Control Group & $48.9 \%$ & $31.7 \%$ & $65.0 \%$ & $48.8 \%$ \\
\hline \multicolumn{5}{|c|}{$\begin{array}{l}\text { Positive feelings regarding physical } \\
\text { activity enjoyment [\% of subjects] }\end{array}$} \\
\hline Small Experimental Group & $76.1 \%$ & $87.1 \%$ & $82.7 \%$ & $86.3 \%$ \\
\hline Large Experimental Group & $83.4 \%$ & $86.1 \%$ & $87.1 \%$ & $91.6 \%$ \\
\hline Control Group & $77.3 \%$ & $87.8 \%$ & $78.9 \%$ & $86.0 \%$ \\
\hline
\end{tabular}

${ }^{*} p<.05$ pre test vs post test. 


\section{DISCUSSION}

The purpose of this study was to ascertain the effect of class size in a health-related fitness course on physical activity behaviors. The limitations of this study were the lack of randomization, unbalanced groups, and self-reported measures. Random assignment among groups was not practical since students selected classes based on need and personal time schedules. Regarding the unbalanced groups, the LE classes were 2 and $1 / 2$ times larger than the SE, which resulted in a similar difference in overall group size. Also, the $\mathrm{C}$ group was restricted to subjects who had never taken the health-related fitness course. Since this course typically is taken as an incoming freshman, the number of $\mathrm{C}$ subjects was smaller than desired despite surveying 14 classes. Although the data were based on self-report, any inaccuracies are assumed to be random and among all groups.

Baseline physical activity measures were not different among groups. The values for mediators and physical activity behaviors were comparable to previously published data among individuals with similar demographics. The quantity (min/week) and quality (MET minutes/week) of vigorous, moderate, and walking activities were found to be similar previously published values (4). Slightly more than one-half of all subjects classified themselves as active based on the stages of change, which is similar to the proportion reported by Sallis and colleagues (13) in Project GRAD. Regarding subject ratings of physical activity enjoyment, about $80 \%$ of the subjects had positive feeling toward physical activity. When the mean rating across all 18 questions were examined, the subject responses were similar to (6) or slightly lower (13) than previously reported among university students.

Based on the findings from the present study, class size in a 15-week health-related fitness course appears to affect mediators (stages of change) and levels of physical activity. The SE group reported larger increases in the quantity $\left(150^{+}\right.$ minutes/week) and quality of physical activity $\left(450^{+}\right.$ MET minutes/week). Unfortunately subjects in the LE group tended to report small reductions in physical activity patterns, excluding moderate activity. Surprisingly, there was a tendency for all groups to report reductions in walking (MET minutes/week). Although it is unclear why this pattern occurred, it is plausible that subjects in the experimental groups began incorporating other moderate activities into their daily lives, thus resulting in the decline for walking specifically. This explanation would not apply for the $\mathrm{C}$ group since all physical activity levels tended to decline, which may be a result of the increased time demands of attending school. The only physical activity measure that increased significantly for the LE group was the proportion of subjects classified in the active stages of change. It is important to note that the change was small $(7.4 \%)$ and occurred in the absence of significant changes in all other physical activity measures. Surprisingly, the SE group failed to report a significant increase for those classified as active; however, there was a positive trend $(9.6 \%, \mathrm{p}=.066)$. There were no changes in self-reported physical activity enjoyment. This can probably be attributed to the relatively high pre test levels reported.

Based on empirical evidence, one would assume that a more effective learning environment would occur in a smaller classroom setting, and the results support this conclusion. Educational research pertaining to the relationship between class size and educational effectiveness in higher education settings has been conducted throughout the last eighty years. These studies have consistently found that small classes are superior to large classes on many measures of educational effectiveness. For example, Macomber and Siegel $(7,8,9)$ found that: (a) knowledge as measured by conventional achievement tests; (b) critical thinking skills; (c) problem solving; (d) student attitudes toward instruction and; (e) retention of knowledge two years later were improved to a greater degree in smaller classes than in more large classes covering the same topics. In summary, a number of research experiments over that last seven to eight decades strongly supported small group instruction over large group instruction in higher education settings.

However, a search of the literature failed to produce any studies addressing the effect of class size on the effectiveness of health-related fitness or other similar type courses. It is well established that exercise behaviors are difficult to change, and numerous stud- 
ies have been conducted to test different theoretical models that have been proposed to explain human behavior regarding health outcomes (3). Effective interventions address not only the desired behavioral change but the mediators of change such as self-efficacy, social support, exercise enjoyment, dealing with barriers, along with others (13). Also effective interventions should be designed to promote multiple physical activity targets such increasing the quantity and quality of individual numerous activities (e.g., walking, moderate, vigorous, strengthening) and/or reducing various inactive behaviors (e.g., time watching television or using a computer) (15).

The greater effectiveness of the smaller class size was probably related to numerous factors. Counterproductive dynamics of large group instructional settings are explicated by McKeachie (11). He stated that, "Because active thinking is so important to learning and retention of learning, constraints upon oral participation [as manifested in large instructional settings] are likely not only to induce passivity but also to be educationally harmful" (11). It can be postulated that an important aspect of the small class setting was the time available for instructorstudent interaction. Regular feedback and encouragement from the instructor can be a valuable tool for eliciting change. The instructor-student relationship is strengthened even in the most rudimentary of tasks of learning student names, which is difficult and sometimes impossible in larger classes. When the instructor addresses students using their names, they tend to be more responsive because they perceive the instructor to be genuinely concerned regarding their health on a personal level. In larger class settings, it is easier for students as individuals to disappear among their classmates. And it is easy for instructors to really never know many of the students on any kind of personal level. Although peer reinforcement can be utilized to systematically encourage behavioral change, the impetus for change potentially might not have been as strong from a colleague compared to the instructor. Generally, peers tend to lack the training and knowledge to provide the necessary support that some students might need to alter their behaviors.

An interesting finding from the present study was the effectiveness of the intervention in small class sizes for women, but not for men. Our results are consistent with findings observed in Project GRAD where the intervention only elicited positive physical activity behavior changes among women. They attributed their findings to the gender difference in baseline values, with men being more active than women. This is consistent with our study where the women had lower baseline values, thus more potential for change, than the men. It is indiscernible as to whether the larger effect for women is due to the lower baseline values or is in some way attributed to the smaller class size. Further research is necessary to determine if different learning environments are more effective for each gender when trying to alter physical activity behaviors.

In conclusion, the results of this study show physical activity behavioral changes are influenced by class size. This finding parallels the broader research findings in higher education settings, that large classes are not as effective as small classes for retention of knowledge, development of critical thinking skills, and most importantly - attitude change (11). Attitudinal changes are the precursors for any behavioral changes and particularly the type of purposeful changes necessary to initiate or further develop healthy lifestyles. Therefore, if a primary goal of health-related fitness courses is to increase participation in physical activity, it would be a prudent policy to limit enrollment in such courses. Since learning outcomes appear to be impaired by large class sizes, more research is necessary to determine the upper threshold class size to ensure students are meeting course objectives.

\section{CORRESPONDÊNCIA}

\section{Mauro V.G. Barros}

Núcleo de Pesquisa em Atividade Física \& Saúde

(NuPAF/CDS)

Campus Universitário, Trindade

88040-900 Florianópolis, SC Brasil

mauro@esef.upe.br 


\section{REFERENCES}

1 Buckworth J. (2001). Exercise adherence in college students: issues and preliminary results. Quest 53:335-345.

2 Centers for Disease Control and Prevention (2001). Increasing physical activity: a report on recommendations of the Task Force on Community Preventive Services. MMWR Morb Mortal Wkly Rep 50 (RR-18):1-16.

3 Dishman RK, Buckworth J. (1996). Increasing physical activity: a quantitative synthesis. Med Sci Sports Exerc 28:706-719.

4 Douglas KA, Collins JL, Warren C, et al. (1995). Results from the 1995 national college health risk behavior survey. Am J College Health 46:55-66.

5 Hensley LD. (2000). Status of basic instruction programs in physical education in American colleges and universities. J Phys Educ Rec Dance 71:536-544.

6 Kendzierski D, DeCarlo KJ. (1991). Physical activity enjoyment scale: two validation studies. J Sport Exerc Psychol 13:50-64.

7 Macomber FG, Siegel L. (1957a). A study of large-group teaching procedures. Educ Res 52:129-133.

8 Macomber FG, Siegel L. (1957b). Experimental study in instructional procedures. Progress Report No. 2. Oxford, OH: Miami University.

9 Macomber FG, Siegel L. (1960). Experimental study in instructional procedures. Final Report. Oxford, OH: Miami University.

10 Marcus BH, Selby, VC, Niaura, RS, Rossi, JS. (1992). Selfefficacy and the stages of exercise behavior change. Res $Q$ Exerc Sport 63:60-66.

11 McKeachie WJ. (1994). Teaching Tips. D.C. Heath and Company. Lexington, MA, 197-200.

12 Nahas MV, Goldfine B, Collins MA. (2003). Determinants of physical activity in adolescents and young adults: the basis for high school and college physical education to promote active lifestyles. Phys Educator 60:42-56.

13 Sallis JF, Calfas KJ, Nichols JF et al. (1999). Evaluation of a university course to promote physical activity: project GRAD. Res Q Exerc Sport 70:1-10.

14 Slattery ML, Edwards SL, Boucher KM, Anderson K, Caan BJ. (1999). Lifestyle and colon cancer: an assessment of factors associated with risk. Am J Epidemiol 150:869-877.

15 US Department of Health and Human Services(1996). Physical activity and health: a report of the Surgeon General. Atlanta, GA: Centers for Disease Control and Prevention.

16 Wannamethee SG, Shaper AG, Walker M, Ebrahim S. (1998). Lifestyle and 15-year survival free of heart attack, stroke, and diabetes in middle-aged British men. Arch Intern Med 158:2433-2440. 